Article

\title{
Biomimetic Catalysts Based on Au@ZnO-Graphene Composites for the Generation of Hydrogen by Water Splitting
}

\author{
Abniel Machín 1,*(D) Juan C. Arango ${ }^{2}(0)$, Kenneth Fontánez ${ }^{2}$, María Cotto ${ }^{2}$, José Duconge ${ }^{2}$, \\ Loraine Soto-Vázquez ${ }^{3}$, Edgar Resto ${ }^{3}$, Florian Ion Tiberiu Petrescu ${ }^{4}\left({ }^{\circ}\right.$, Carmen Morant $^{5}$ and \\ Francisco Márquez ${ }^{2}$ (1) \\ 1 Arecibo Observatory, Universidad Ana G. Méndez-Cupey Campus, San Juan, PR 00926, USA \\ 2 Nanomaterials Research Group, School of Natural Sciences and Technology, Universidad Ana G. \\ Méndez-Gurabo Campus, Gurabo, PR 00778, USA; jcarangolozano@hotmail.com (J.C.A.); \\ kenneth.fontanez@gmail.com (K.F.); mcotto48@uagm.edu (M.C.); jduconge@uagm.edu (J.D.); \\ fmarquez@uagm.edu (F.M.) \\ 3 Materials Characterization Center Inc., Molecular Sciences Research Center, University of Puerto Rico, \\ San Juan, PR 00926, USA; sotol6@uagm.edu (L.S.-V.); edgar.resto@upr.edu (E.R.) \\ 4 IFToMM-ARoTMM, Bucharest Polytechnic University, 060042 Bucharest, Romania; \\ tiberiuflorianion@gmail.com \\ 5 Department of Applied Physics, Autonomous University of Madrid, 28041 Madrid, Spain; c.morant@uam.es \\ * Correspondence: machina1@uagm.edu
}

Received: 8 July 2020; Accepted: 19 August 2020; Published: 21 August 2020

check for updates

\begin{abstract}
For some decades, the scientific community has been looking for alternatives to the use of fossil fuels that allow for the planet's sustainable and environmentally-friendly development. To do this, attempts have been made to mimic some processes that occur in nature, among which the photosystem-II stands out, which allows water splitting operating with different steps to generate oxygen and hydrogen. This research presents promising results using synthetic catalysts, which try to simulate some natural processes, and which are based on Au@ZnO-graphene compounds. These catalysts were prepared by incorporating different amounts of gold nanoparticles ( $1 \mathrm{wt} . \%, 3 \mathrm{wt} . \%$, $5 \mathrm{wt} . \%, 10 \mathrm{wt} . \%)$ and graphene (1 wt.\%) on the surface of synthesized zinc oxide nanowires ( $\mathrm{ZnO}$ $\mathrm{NWs}$ ), and zinc oxide nanoparticles ( $\mathrm{ZnO} \mathrm{NPs}$ ), along with a commercial form (commercial $\mathrm{ZnO}$ ) for comparison purposes. The highest amount of hydrogen $(1127 \mu \mathrm{mol} / \mathrm{hg})$ was reported by $\mathrm{ZnO}$ NWs with a gold and graphene loadings of $10 \mathrm{wt} . \%$ and $1 \mathrm{wt} . \%$, respectively, under irradiation at $400 \mathrm{~nm}$. Quantities of $759 \mu \mathrm{mol} / \mathrm{hg}$ and $709 \mu \mathrm{mol} / \mathrm{hg}$ were obtained with catalysts based on ZnO NPs and commercial $\mathrm{ZnO}$, respectively. The photocatalytic activity of all composites increased with respect to the bare semiconductors, being 2.5 times higher in $\mathrm{ZnO}$ NWs, 8.8 times higher for $\mathrm{ZnO}$ NPs, and 7.5 times higher for commercial $\mathrm{ZnO}$. The high photocatalytic activity of the catalysts is attributed, mainly, to the synergism between the different amount of gold and graphene incorporated, and the surface area of the composites.
\end{abstract}

Keywords: hydrogen production; $\mathrm{ZnO}$; gold nanoparticles; graphene; water splitting

\section{Introduction}

If you were asking to identify one of the many challenges that our world is facing right now, you would probably say climate change, energy production, or sustainability. Most of these problems are directly related to the continuous growth of the world population and the use of fossil fuels as our primary energy source [1]. 
In the case of finding a clean and renewable energy source, multiple candidates have been proposed over the years. One of them is hydrogen. Some of the properties that make hydrogen a good candidate to replace fossil fuels are its abundance, high energy yield, storage capability, and environmental compatibility [2]. Hydrogen is the most abundant element in the universe and can be found in water and biomass. If compared to hydrocarbons, hydrogen can produce 2.75 times more energy, can be stored as a solid, liquid, or gas, and if it is combined with oxygen, no harmful and toxic gases such as nitrogen oxides $\left(\mathrm{NO}_{\mathrm{x}}\right)$ or sulfur oxides $\left(\mathrm{SO}_{\mathrm{x}}\right)$ are release to the atmosphere [2].

Unfortunately, the vast majority of hydrogen that is produced in the world, comes from a process known as natural gas reforming [3]. As the name says, this process uses natural gas, methane $\left(\mathrm{CH}_{4}\right)$, as the source to obtain hydrogen. This process releases carbon dioxide $\left(\mathrm{CO}_{2}\right)$ to the atmosphere, increasing the amount of this greenhouse gas and exacerbating global warming [3].

Photosynthesis offers an excellent model for designing an artificial solar energy conversion system for clean fuel generation. In nature, electrons are provided to the reaction center of the photosystem-II in four consecutive proton coupled electron transfer steps, and ultimately appear as reduced carbon derived products that form the basis of biological activity. Inspired by natural principles, for decades there has been a continuous effort to design artificial photosynthetic assemblies based on the use of solar energy to generate oxygen and hydrogen by water splitting [4-6]. Over the years, multiple candidates such as titanium dioxide $\left(\mathrm{TiO}_{2}\right)$, zinc oxide $(\mathrm{ZnO})$, tungsten trioxide $\left(\mathrm{WO}_{3}\right)$, cadmium sulfide (CdS), among others [7-11] have been used to produce hydrogen via water splitting [12,13]. From all these photocatalysts, $\mathrm{TiO}_{2}$ has been extensively studied over the years mainly due to its chemical stability, abundance, non-toxicity, and high hydrogen yield [12].

Similar to titanium oxide, $\mathrm{ZnO}$ has also been demonstrated to be chemically stable, easy to produce, non-toxic, abundant, and environmentally-friendly $[9,10]$, although unlike titanium dioxide, $\mathrm{ZnO}$ has been widely used for the degradation of organic pollutants and energy storage [14-16]. Some authors $[17,18]$ consider that $\mathrm{ZnO}$ shows some disadvantages for the production of hydrogen by water splitting, especially the recombination of photogenerated electron-hole pairs, fast backward reaction, and the inability to use visible light. To try to solve these limitations, different approaches have been implemented over the years. One of them has been the incorporation of noble metal to the surface of the catalysts $[17,18]$. Among noble metals, gold has gained much attention since the 1980s because of its wide range of applications, including electronics, photodynamic therapy, delivery of therapeutic agents, sensors, probes, diagnostics, and catalysis [19,20]. Multiple pathways to incorporate gold nanoparticles (Au NPs) can be found in the literature. Methods such as coprecipitation [21], chemical reduction [22], phytochemical reduction [23], and the hydrothermal approach [24] have been successfully implemented over the years. All these synthesis procedures take into account parameters such as the preparation procedure, gold loading (percentage of gold weight on the material), particle size, dispersion (percentage of support surface covered by gold), and shape of the particles.

Recently, another approach that has drawn a lot of attention is the use of graphene as a co-catalyst for the production of hydrogen via water splitting. Graphene has unique properties such as high thermal conductivity, excellent mobility of charge carriers, large surface area, and good mechanical stability [25]. As a co-catalyst, graphene has significant advantages, including that it (i) provides a support for anchoring well-dispersed metallic or oxide nanoparticles; (ii) works as a highly conductive matrix for enabling good contact throughout the matrix; (iii) induces an easy electron transfer from the conduction band of the semiconductor to graphene because of the large energy level offset formed at the interface, leading to an efficient charge separation; and (iv) acts as an efficient co-catalyst for $\mathrm{H}_{2}$ evolution because of its large specific surface area and superior electron mobility [26].

There are several approaches reported on the literature to prepare graphene-ZnO composites. For example, Tien and group [27] used a microwave-assisted solvothermal process, whereas Ong and group [28] reported the preparation of the composites using a chemical deposition-calcination approach.

There is very limited information in the literature on the production of hydrogen via water splitting by combining graphene and $\mathrm{ZnO}$. Haldorai and Shim [29] reported the production of hydrogen via 
water splitting by employing a supercritical fluid mediated synthesis. They reported that the composites exhibited enhanced photocatalytic activity, because the $\mathrm{ZnO}$ particles on the graphene sheets captured light energy and acted as electron mediators.

To our knowledge, no results have been reported on the incorporation of graphene and gold nanoparticles on the surface of $\mathrm{ZnO}$ for the production of hydrogen by water splitting. The information found in the literature is very limited and focuses on the degradation of dyes and nitrobenzene under visible and UV light. For example, Zeng et al. [30] and Wang et al. [31] reported high photocatalytic activity for the degradation of rhodamine B and methylene blue, respectively. They found that the combination of gold and graphene on the surface of $\mathrm{ZnO}$ allows the system to use visible and UV light, and more importantly, greatly improves the degradation percentage compared to pure $\mathrm{ZnO}$ and $\mathrm{Au}-\mathrm{ZnO}$. On the other hand, Roy et al. [32] reported on the efficient reduction of nitrobenzene under UV and visible light, in which the catalyst reduced $97.8 \%$ of the original compound.

Due to the lack of information on the production of hydrogen by water splitting using $\mathrm{Au} @ \mathrm{ZnO}-$ graphene composites, the objectives of this research focused mainly on (i) synthesizing ZnO with different morphologies (nanoparticles and nanowires); (ii) incorporating different amounts of gold nanoparticles ( $1 \mathrm{wt} . \%, 3 \mathrm{wt} \%$, $5 \mathrm{wt} . \%$, and $10 \mathrm{wt} . \%$ ) and graphene (1 wt.\%) to the surface of the as-synthesized catalysts and to its commercial form; and (iii) characterizing the photocatalytic activity of the compounds by studying the production of hydrogen by water splitting under UV-vis radiation. Au@ZnO-graphene-based catalysts were characterized using HRTEM, UV-vis spectroscopy, BET surface area, XRD, XPS, Raman spectroscopy, and GC-TCD.

\section{Materials and Methods}

\subsection{Reagents}

All reagents were used as received and all the solutions were prepared using deionized water (Milli-Q water, $18.2 \mathrm{M} \Omega \mathrm{cm}^{-1}$ at $\left.25^{\circ} \mathrm{C}\right) . \mathrm{Zn}\left(\mathrm{CH}_{3} \mathrm{COO}\right)_{2} \bullet 2 \mathrm{H}_{2} \mathrm{O}\left(98+\%\right.$, ACS Reagent), $\mathrm{HAuCl}_{4} \bullet 3 \mathrm{H}_{2} \mathrm{O}$ (ACS Reagent, 49.0+\% Au basis), ethanol (95\%), and $\mathrm{NaBH}_{4}$ (+99.9\%) were provided by Sigma Aldrich (Milwaukee, Wisconsin USA). $\mathrm{NaOH}(98+\%)$ and $\mathrm{ZnO}(99.99 \%)$ were acquired from Alfa Aesar (Ward Hill, Massachusetts USA). Graphene (99\%) was provided by Cheap-Tubes (Grafton, Vermont USA). For photocatalytic experiments, $\mathrm{Na}_{2} \mathrm{~S}(99.9+\%)$ and $\mathrm{Na}_{2} \mathrm{SO}_{3}(98+\%)$ were obtained from Sigma Aldrich (Milwaukee, Wisconsin USA) and used as sacrificial reagents.

\subsection{Synthesis of Nanomaterials}

$\mathrm{ZnO}$ nanowires ( $\mathrm{ZnO}$ NWs) were obtained according the method described elsewhere [33]. Zinc oxide nanoparticles (ZnO NPs) were synthesized following the method used by Nejati et al. [34]. The deposition of Au NPs and graphene on the surface of ZnO NWs, ZnO NPs, and the commercial $\mathrm{ZnO}$ (commercial $\mathrm{ZnO}$ ) was based on the method described by Naldoni et al. [35], later modified by Wang et al. [15]. In a typical synthesis, $200 \mathrm{mg}$ of the product (ZnO NWs, ZnO NPs, and commercial $\mathrm{ZnO}$ ) containing the gold nanoparticles was dispersed in a solution containing $10 \mathrm{~mL}$ of ethanol and $40 \mathrm{~mL}$ of deionized water, and the mixture was vigorously stirred for $30 \mathrm{~min}$. Subsequently, $2 \mathrm{mg}$ of graphene was added, and the suspension was kept under stirring for $1 \mathrm{~h}$. After that, the product was collected and centrifuged 3 times with deionized water and dried overnight to $60{ }^{\circ} \mathrm{C}$. Finally, the product was collected, sealed, and stored at room temperature. The different Au@ZnO-graphene composites were identified as $x \% \mathrm{Au} @ \mathrm{ZnO}$-graphene. The numbers $(x \%)$ correspond to the weight percentage of $\mathrm{Au}$ NPs in the sample. In all cases, the amount of graphene was $1 \mathrm{wt} . \%$.

\subsection{Characterization of the Catalysts}

The catalysts were characterized by high resolution transmission electron microscopy (HRTEM), using a JEOL 3000F. XPS measurements were performed on an ESCALAB 220i-XL spectrometer, using the non-monochromated $\mathrm{Mg} \mathrm{K} \alpha(1253.6 \mathrm{eV})$ radiation of a twin-anode, operating at $20 \mathrm{~mA}$ and $12 \mathrm{kV}$ 
in the constant analyzer energy mode, with a PE of $40 \mathrm{eV}$. Brunauer Emmett Teller (BET) specific areas were measured using a Micromeritics ASAP 2020, according to $\mathrm{N}_{2}$ adsorption isotherms at $77 \mathrm{~K}$. Raman (DXR Thermo Raman Microscope, employing a $532 \mathrm{~nm}$ laser source at $5 \mathrm{~mW}$ power and a nominal resolution of $5 \mathrm{~cm}^{-1}$ ) and X-ray diffraction (Bruker D8 Discover X-ray diffractometer, operating at $40 \mathrm{kV}$ and $40 \mathrm{~mA}$ in the range of $30-75^{\circ}$ at $1^{\circ} \mathrm{min}^{-1}$ ) were also used. UV-vis spectroscopy (Shimadzu UV-2401PC) was used as a complementary technique to determine the absorption edge of the catalysts.

\subsection{Photocatalytic Experiments}

The production of hydrogen via water splitting was measured by adding $50 \mathrm{mg}$ of the $x \% \mathrm{Au} @ \mathrm{ZnO}-$ graphene catalyst into $100 \mathrm{~mL}$ of deionized water and transferring this suspension to a $250 \mathrm{~mL}$ quartz reactor. Then, solutions of $0.02 \mathrm{M} \mathrm{Na}_{2} \mathrm{SO}_{3}$ and $0.4 \mathrm{M} \mathrm{Na} 2 \mathrm{~S}$ were added as sacrificial reagents. After that, the solution was thermostatized at $20{ }^{\circ} \mathrm{C}$ and purged for 30 min with nitrogen $\left(\mathrm{N}_{2}\right)$. Finally, the reaction mixture was irradiated with $\mathrm{UV}$-vis light for $2 \mathrm{~h}$ using different filters to select the appropriate wavelength $(280 \mathrm{~nm}, 320 \mathrm{~nm}, 400 \mathrm{~nm}$, and $500 \mathrm{~nm})$. The produced hydrogen was quantified by gas chromatography (GC), using a thermal conductivity detector (GC-TCD, Perkin-Elmer Clarus 600) [18].

\section{Results and Discussion}

\subsection{Characterization of Catalysts}

The characterization of the different ZnO supports and Au@ZnO-based catalysts was shown in our previous research [18]. On these catalysts, $1 \mathrm{wt}$ \% graphene was incorporated. Figure 1 shows the HRTEM images and the selected area electron diffraction (SAED) patterns of the 10\%Au@commercial ZnO-graphene (Figure 1A), 10\%Au@ZnO NPs-graphene (Figure 1B), and 10\%Au@ZnO NWs-graphene (Figure 1C) composites. The 10\%Au@commercial ZnO-graphene composite consisted of non-homogenous particles with different sizes (lengths and diameters greater than $50 \mathrm{~nm}$ ) and shapes. Homogeneous spherical gold nanoparticles, with diameters of less than ca. $10 \mathrm{~nm}$, were distributed on the surface of the catalyst. Graphene sheets of different sizes were also distributed unevenly through the sample. According to Wang et al. [15], it is believed that close and homogeneous contact between $\mathrm{Au}$, support, and graphene favors the transfer of photogenerated electrons between them, thus improving charge separation and photocatalytic efficiency. As in the case of the commercial catalyst, the $10 \% \mathrm{ZnO}$ NPs-graphene catalyst showed non-homogeneous particles of different sizes and shapes, with lengths and diameters greater than $50 \mathrm{~nm}$. The non-homogeneous gold nanoparticles were unevenly distributed throughout the sample, presenting a spherical morphology with diameters of less than $10 \mathrm{~nm}$. Graphene was also unevenly distributed throughout the sample and served as a support for $\mathrm{ZnO}$ particles and gold nanoparticles. In the case of the 10\%Au@ZnO NWs-graphene catalyst, the incorporation of graphene and gold considerably modified the pristine material. The catalyst consisted of non-homogeneous wires, with an estimated length greater than $300 \mathrm{~nm}$ and diameters above $50 \mathrm{~nm}$. Gold nanoparticles, with spherical morphology and diameters of less than $10 \mathrm{~nm}$, were distributed throughout the sample. Graphene also appeared to be unevenly distributed in the sample, but had intimate contact with the gold nanoparticles and the support. SAED patterns of synthesized gold-graphene-based composites were characteristic of monocrystalline materials.

Table 1 shows the BET surface area results of the different Au@ZnO-graphene composites. The incorporation of the different amounts of Au NPs (1 wt.\%, 3 wt.\%, 5 wt.\%, and 10 wt. \%), along with graphene (1 wt.\%), increased the surface area of all the catalysts when compared to the unmodified supports [18]. This enhancement suggests an intimate contact between the incorporated materials and the support [35]. Graphene, as explained above, has a very high surface area $\left(\sim 2000 \mathrm{~m}^{2} \mathrm{~g}^{-1}\right)$, which can contribute to increasing the surface area of composites. However, since the amount of graphene, when compared to gold, was minimum, the enhancement of the surface areas of the catalysts could be 
primarily attributed to the Au NPs. The highest surface area of the commercial support was measured to be $65 \mathrm{~m}^{2} \mathrm{~g}^{-1}$ and was obtained with the 10\%Au@ commercial ZnO-graphene. This represents an increase of $47 \mathrm{~m}^{2} \mathrm{~g}^{-1}$ if compared to the unmodified commercial $\mathrm{ZnO}$ support. The highest surface area of the Au@ZnO NPs-graphene composites was $117 \mathrm{~m}^{2} \mathrm{~g}^{-1}$ and was measured in the $10 \% \mathrm{Au} @ \mathrm{ZnO}$ NPs-graphene catalyst, showing a difference of $50 \mathrm{~m}^{2} \mathrm{~g}^{-1}$ if compared to the result obtained with the unmodified ZnO NPs. For the Au@ZnO NWs-graphene composites, the highest surface area was $247 \mathrm{~m}^{2} \mathrm{~g}^{-1}$, obtained by the 10\% Au@ZnO NWs-graphene catalyst. This represents a difference of $80 \mathrm{~m}^{2} \mathrm{~g}^{-1}$ if compared to the surface area of the unmodified ZnO NWs $\left(167 \mathrm{~m}^{2} \mathrm{~g}^{-1}\right)$.
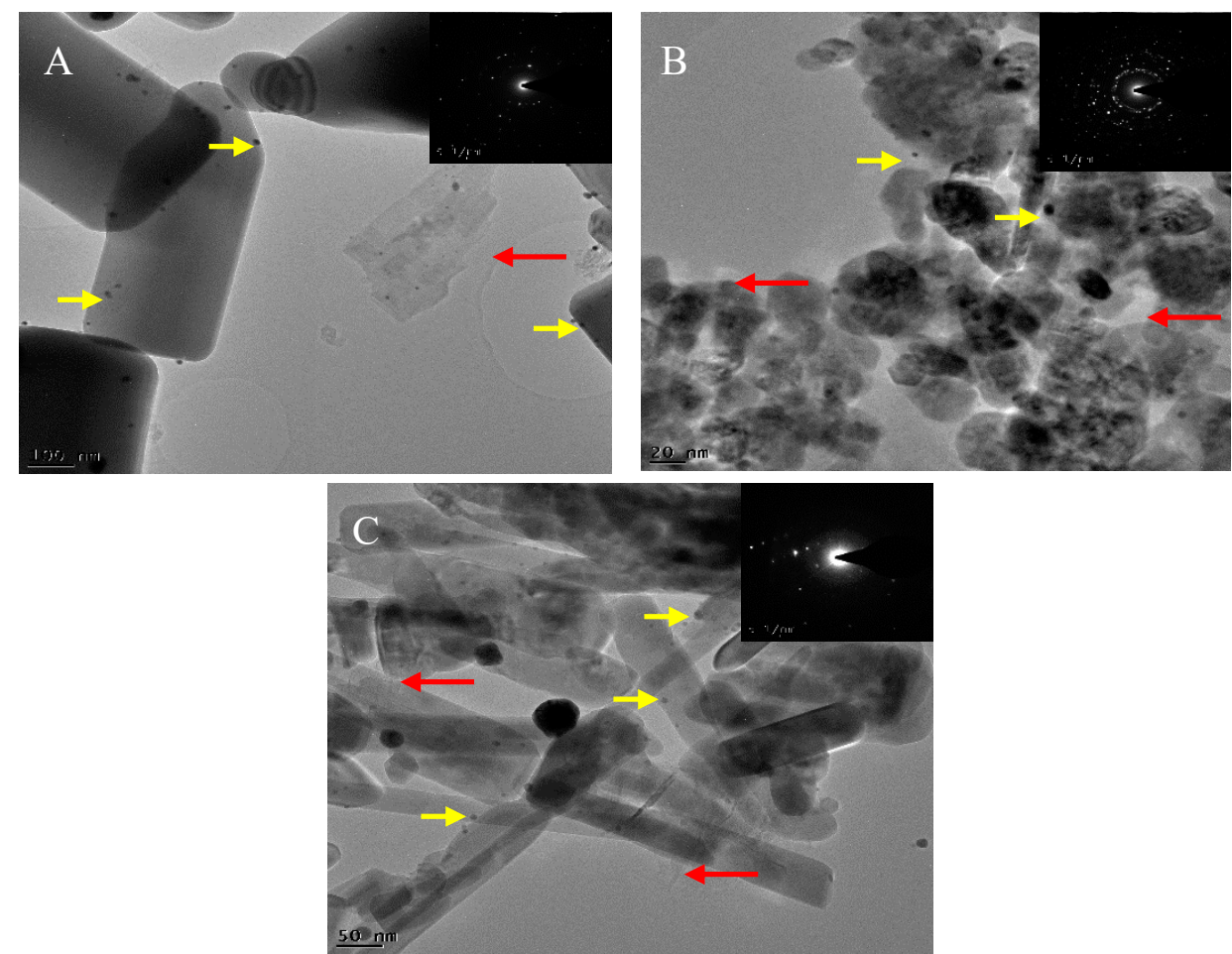

Figure 1. High resolution transmittance electron microscopy (HRTEM) images of 10\%Au@commercial ZnO-graphene (A), 10\%Au@ZnO NPs-graphene (B), and 10\%Au@ZnO NWs-graphene (C). The red and yellow arrows indicate the presence of graphene and gold, respectively, and the insets correspond to the selected area of electron diffraction (SAED) patterns.

Table 1. BET surface area of the Au@ZnO-graphene composites.

\begin{tabular}{cccc}
\hline & $\begin{array}{c}\text { Commercial ZnO } \\
\left(\mathbf{m}^{\mathbf{2}} \mathbf{g}^{\mathbf{- 1}}\right)\end{array}$ & $\begin{array}{c}\text { ZnO NPs } \\
\left(\mathbf{m}^{\mathbf{2}} \mathbf{g}^{-\mathbf{1}}\right)\end{array}$ & $\begin{array}{c}\text { ZnO NWs } \\
\left(\mathbf{m}^{\mathbf{2}} \mathbf{g}^{-\mathbf{1}}\right)\end{array}$ \\
\hline Unmodified & 18 & 67 & 167 \\
$\mathbf{1 \% A u - G r a p h e n e ~ *}$ & 48 & 96 & 201 \\
3\%Au-Graphene * $^{*}$ & 51 & 103 & 212 \\
$\mathbf{5 \% A u - G r a p h e n e ~ *}$ & 56 & 109 & 223 \\
$\mathbf{1 0 \% A u - G r a p h e n e ~ *}$ & 65 & 117 & 247 \\
\hline
\end{tabular}

* The amount of graphene in all the catalysts was $1 \mathrm{wt} . \%$.

The XRD patterns of the different composites with a gold loading of $10 \mathrm{wt} . \%$ are shown in Figure 2. The characteristic peaks of wurtzite crystalline phase (ca. 32.0 $(100), 34.8^{\circ}(002), 36.0^{\circ}(101), 47.5^{\circ}$ $\left.(102), 56.2^{\circ}(110), 62.8^{\circ}(103), 66.0^{\circ}(200), 67.5^{\circ}(112), 68.8^{\circ}(201)\right)$ were observed in all the catalysts [16]. In all cases, reflections at $38.2^{\circ}$ and $44.4^{\circ}$ were observed, which have been associated with Au (111) and (200), respectively [20], indicating that $\mathrm{Au}^{3+}$ had been reduced to $\mathrm{Au}^{0}$, with the usual fcc structure. Au NPs showed other characteristic peaks of lower intensity at $64.7^{\circ}(220)$ and $77.8^{\circ}(311)$, which could 
not be identified in the catalysts. Applying the Scherrer formula [36], an estimate of the mean size of the gold nanoparticles could be made, providing a value of ca. $15 \mathrm{~nm}$ in all cases. This value is very close to that determined by HRTEM $(<20 \mathrm{~nm})$. Graphene, on the other hand, has characteristic peaks at ca. $24.5^{\circ}$ and $44.2^{\circ}$ [24]. These peaks were not identified in any of the composites. The amount of graphene incorporated to the Au@ZnO-graphene composites was very low when compared to the amount of the support and gold loading, and it is possible that the signal emitted by graphene was very weak and not able to be detected by the instrument.

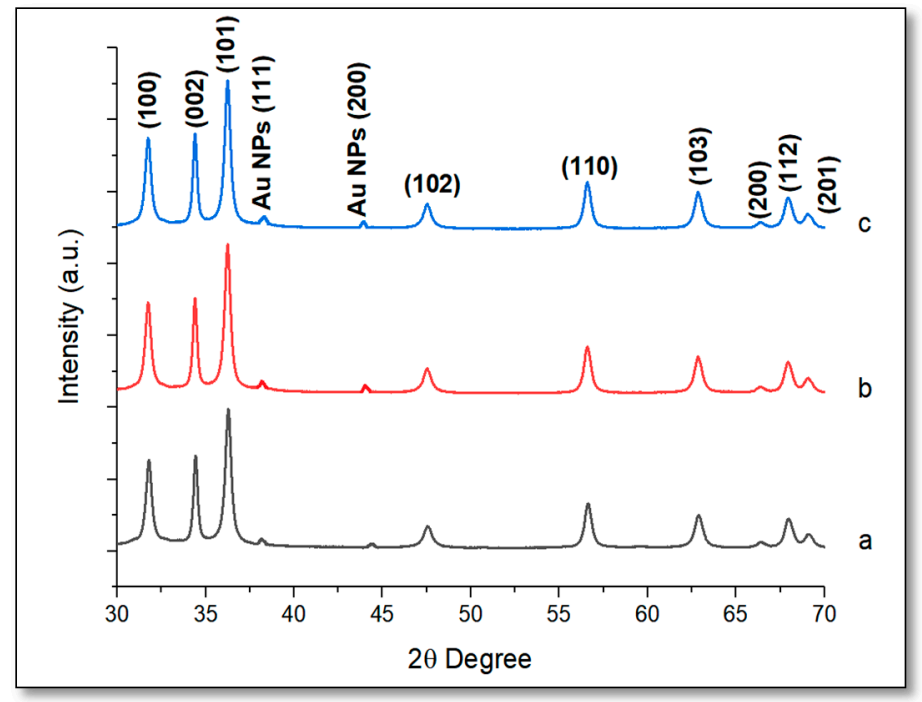

Figure 2. X-ray diffractometer (XRD) diffraction patterns for 10\% Au@commercial ZnO-graphene (a); 10\%Au@ZnO NPs-graphene (b); and 10\%Au@ZnO NWs-graphene (c).

The Au@ZnO-graphene composites containing gold loadings of 5 wt.\% and 10 wt.\% were characterized by Raman spectroscopy (see Figure 3). Graphene has two characteristics peaks at ca. $1350.0 \mathrm{~cm}^{-1}$ and $1595.0 \mathrm{~cm}^{-1}$, known as D- and G-bands, respectively [37]. The D-band $\left(1350 \mathrm{~cm}^{-1}\right)$ has been related to the defects and structural disorder in graphene sheets, whereas the G-band $\left(1595 \mathrm{~cm}^{-1}\right)$ has been ascribed to the stretching of the $\mathrm{sp}^{2}$ hybridized carbon-carbon bonds [37]. These two bands were observed in all the gold-graphene composites, including those with gold loadings of $1 \mathrm{wt} . \%$ and $3 \mathrm{wt} . \%$. The ratio of the intensity between the D- and G-band is a measure of the degree of disorder in graphene [38]. The narrow strong band at ca. $437.0 \mathrm{~cm}^{-1}\left(E_{2}\right.$ modes) is present in all the composites and it has been ascribed to motion of $\mathrm{Zn}$ in the wurtzite phase [16]. No gold bands were found for any of the composites.

$\mathrm{Au} @ \mathrm{ZnO}$-graphene composites, with gold loadings of $5 \mathrm{wt} . \%$ and $10 \mathrm{wt} . \%$, were also characterized by UV-vis spectroscopy (Figure 4). All the catalysts presented a similar absorption range between $325 \mathrm{~nm}$ and $400 \mathrm{~nm}$, showing a maximum at ca. $370 \mathrm{~nm}$. Interestingly, despite the introduction of graphene and gold, all the composites had almost the same absorption edge as the unmodified catalysts, indicating that there was a consistent band gap of nanocrystalline $\mathrm{ZnO}$ within the Au@ZnO-graphene composites. This suggests that no carbon species were incorporated into the lattice of $\mathrm{ZnO}$. Because the impurity level would have shifted the absorption edge to a higher wavelength [39]. No gold peaks $(\sim 520-580 \mathrm{~nm})$ were detected for any of the gold loadings incorporated. This might be attributed to the high dispersity of the Au NPs through the samples. 


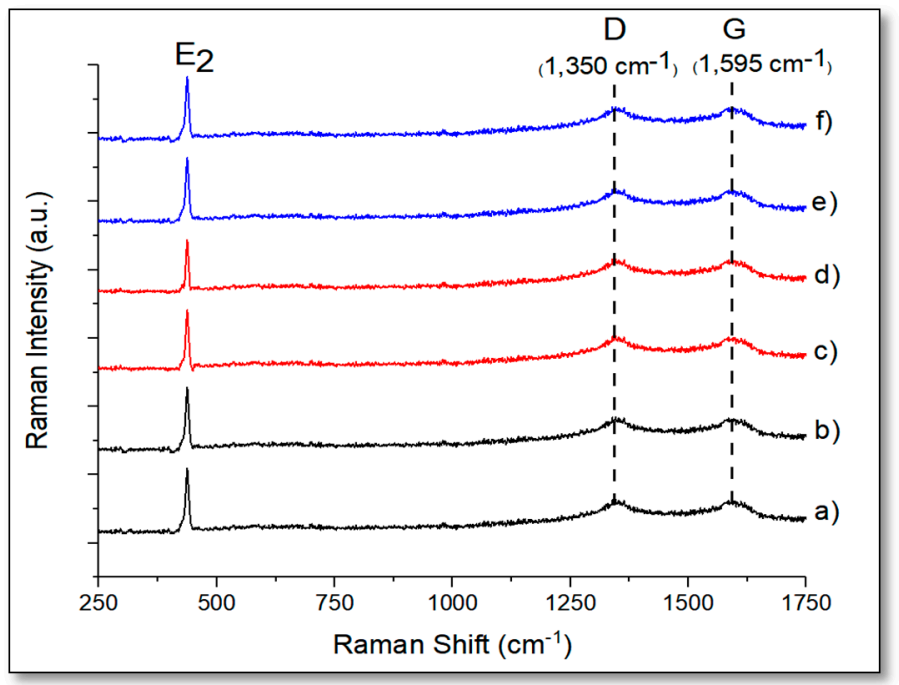

Figure 3. Raman spectra of 5\%Au@commercial ZnO-graphene (a); 10\%Au@commercial ZnO-graphene (b); 5\%Au@ZnO NPs-graphene (c); 10\%Au@ZnO NPs-graphene (d); 5\%Au@ZnO NWs-graphene (e); and 10\%Au@ZnO NWs-graphene (f).

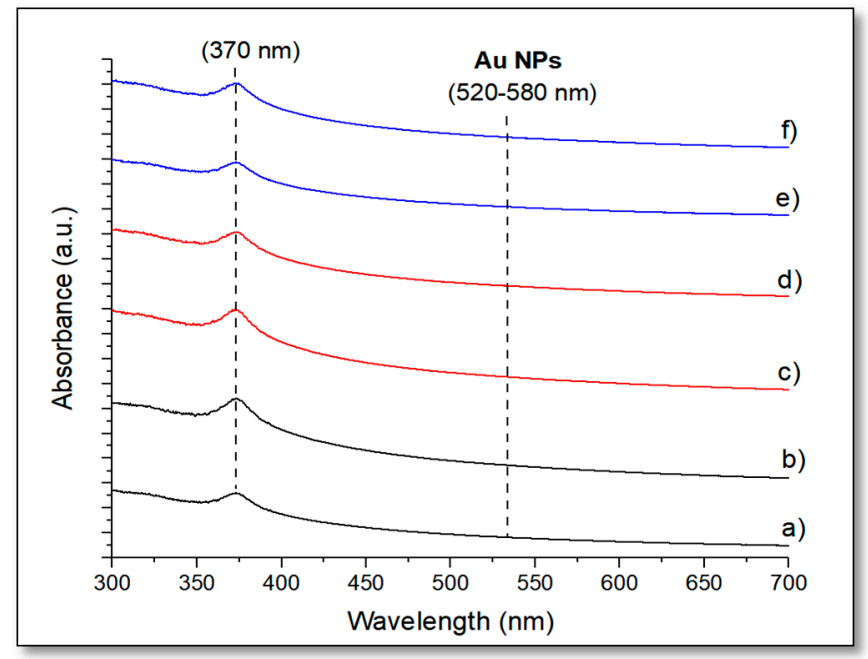

Figure 4. Ultraviolet-visible light (UV-vis) spectra of different composites: 5\%Au@commercial ZnO-graphene (a); 10\%Au@commercial ZnO-graphene (b); 5\%Au@ZnO NPs-graphene (c); 10\%Au@ZnO NPs-graphene (d); 5\%Au@ZnO NWs-graphene (e); and 10\%Au@ZnO NWs-graphene (f).

The catalysts were also characterized by XPS. Figure 5 shows the most relevant spectra of 10\%Au@ZnO NWs-graphene and 10\%Au@ZnO NPs-graphene. In both systems (Figure 5a,e), the $\mathrm{O} 1 \mathrm{~s}$ showed a main peak at ca. $530.2 \mathrm{eV}$, which was assigned to $\mathrm{O}^{2-}$ ions in the $\mathrm{Zn}-\mathrm{O}$ bonds, and a shoulder around $531.5 \mathrm{eV}$, assigned to $\mathrm{O}^{2-}$ ions in the oxygen deficient regions, respectively [18]. As observed, the contribution of this secondary peak was clearly greater in $\mathrm{ZnO} N W$ s than in $\mathrm{ZnO}$ NPs. As it will be shown later, the highest reactivity was observed in catalysts based on ZnO NWs, so this behavior could be justified thanks to the existence of crystalline defects, as already described in previous works [18]. In fact, surface defects in crystalline $\mathrm{ZnO}$ affect its electrical properties, increasing electrical conductivity, which undoubtedly could have positive effects on photocatalysis with these materials. In both catalysts, the $\mathrm{Zn} 2 \mathrm{p}_{3 / 2}$ spectra showed a single component that was unambiguously assigned to $\mathrm{Zn}^{2+}$ in $\mathrm{ZnO}$ (see Figure $\left.5 \mathrm{~b}, \mathrm{f}\right)$. The presence of metallic gold $\left(\mathrm{Au}^{0}\right)$ was evidenced by the presence of a doublet in the emission peak at ca. $84.0 \mathrm{eV}\left(4 \mathrm{f}_{7 / 2}\right)$ and $87.7 \mathrm{eV}\left(4 \mathrm{f}_{5 / 2}\right)$ (Figure $\left.5 \mathrm{c}, \mathrm{g}\right)$ [40]. No components were observed that could show the presence of $\mathrm{Au}^{3+}$, coming from the precursor $\left(\mathrm{HAuCl}_{4} \bullet 3 \mathrm{H}_{2} \mathrm{O}\right)$, which evidenced the complete reduction of gold. Figure $5 \mathrm{~d}$, h shows the transition 
corresponding to C1s. The main peak observed at ca. $284.6 \mathrm{eV}$ was assigned to the carbon backbone of aliphatic/aromatic $\left(\mathrm{sp}^{3} / \mathrm{sp}^{2}\right)$ carbons, while the component indicated by an arrow, around $286.0 \mathrm{eV}$ could be attributed to carbon in $\mathrm{C}-\mathrm{O}$ and $\mathrm{C}-\mathrm{O}-\mathrm{C}$ groups [41,42], and to contamination by adsorption of oxidized species $\left(\mathrm{CO}, \mathrm{CO}_{2}\right)$.
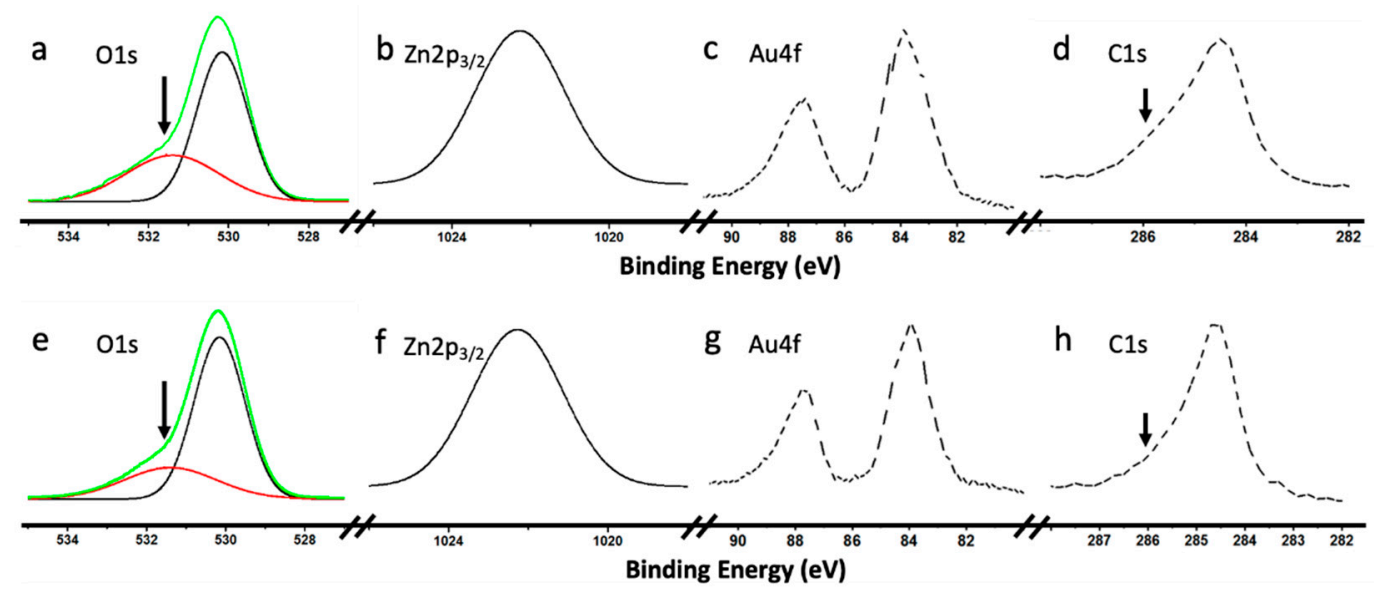

Figure 5. X-ray photoelectron spectroscopy (XPS) spectra of Zn 2 $\mathrm{p}_{3 / 2}, \mathrm{O} 1 \mathrm{~s}, \mathrm{Au} 4 \mathrm{f}$, and C1s taken from as-grown Au@ZnO NWs-graphene (a-d), and Au@ZnO NPs-graphene (e-h).

\subsection{Photocatalytic Hydrogen Production Via Water Splitting}

Figure 6 shows the photocatalytic hydrogen production via water splitting of the different catalysts under irradiation at $280 \mathrm{~nm}$ (Figure 6a), $320 \mathrm{~nm}$ (Figure 6b), $400 \mathrm{~nm}$ (Figure 6c), and $500 \mathrm{~nm}$ (Figure 6d). The maximum hydrogen production of the unmodified $\mathrm{ZnO}$ catalysts was $442 \mu \mathrm{mol} / \mathrm{hg}$ and was obtained with ZnO NWs by irradiation at $280 \mathrm{~nm}$. This high hydrogen production from ZnO NWs was not expected, especially when compared to the maximum hydrogen production of ZnO NPs (86 $\mu \mathrm{mol} / \mathrm{hg})$ and the commercial $\mathrm{ZnO}(94 \mu \mathrm{mol} / \mathrm{hg})$. According to a study by Zhang et al. [16], one-dimensional nanostructures, such as nanowires, can enhance the photocatalytic activity due to their large surface-to-volume ratio as compared to other morphologies. Furthermore, $\mathrm{ZnO}$ is considered a promising material for solar cells due to the fast electron transport, with reduced recombination loss, and its ease of crystallization [16].

Under irradiation at $320 \mathrm{~nm}$, the hydrogen production of ZnO NWs (365 $\mathrm{mmol} / \mathrm{hg})$ decreased when compared to that obtained at $280 \mathrm{~nm}$, but then increased again $(427 \mu \mathrm{mol} / \mathrm{hg})$ at $400 \mathrm{~nm}$. This was not expected either since the wide band gap energy of $\mathrm{ZnO}$ (3.37 eV for wurtzite) does not favor the production of hydrogen under visible light. Different studies $[16,43,44]$ have found that surface defects and oxygen vacancies in photocatalysts can play a significant role in their photocatalytic activity. Crystalline defects in $\mathrm{ZnO}$ nanowires exist primordially due to oxygen vacancies. Even more, these studies have found that nanoparticles with crystalline defects can exhibit visible light activity even without doping them with transition metals.

Both $\mathrm{ZnO}$ NPs and the commercial $\mathrm{ZnO}$ obtained similar results in all the wavelengths that were evaluated. At $500 \mathrm{~nm}$, the hydrogen production of the unmodified catalysts was almost zero, with the exception of $\mathrm{ZnO}$ NWs that obtained a high value of $350 \mu \mathrm{mol} / \mathrm{hg}$, showing high catalytic activity. Incorporation of gold and graphene greatly increased hydrogen production in both the UV and visible regions of all the composites. The presence of co-catalysts such as Au and graphene improve the charge separation and suppresses the recombination of excited photogenerated carriers, resulting in a better evolution of $\mathrm{H}_{2}$ [26]. Different studies [45-47] have demonstrated that when semiconductors, such as $\mathrm{ZnO}$, are doped with noble metal or metal ions, they exhibit a negative shift in the Fermi level that implies a greater degree of electron accumulation in Au-loaded. Thus, such a shift in the Fermi level improves the composite system and enhances the efficiency of the interfacial charge-transfer process. These improvements are in turn associated with a considerable enhancement of the electric 
near-field [45]. This activity relates strongly to the size and shape-dependent surface charge oscillation known as surface plasmon resonance (SPR) in the presence of light irradiation [26]. Furthermore, the incorporation of graphene on semiconductors creates the $\mathrm{p}-\mathrm{n}$ junction, which also improves the separation of photogenerated charges $[26,48]$. The photogenerated holes that were created are then scavenged by the sacrificial agent $\left(\mathrm{S}^{2-} / \mathrm{SO}_{3}{ }^{2-}\right)$, and the electrons are excited to the conduction band. Electrons transferred from the conduction band of the semiconductor are injected into the graphene because graphene has a slightly lower redox potential than the semiconductor conduction band $[26,48]$. Graphene has a high charge carrier transfer and mobility as a result of its $\pi$-conjugated structure, and hence Au nanoparticles dispersed on the graphene can also accept electrons and act as active sites to react with adsorbed $\mathrm{H}^{+}$ions for $\mathrm{H}_{2}$ evolution $[26,48]$.

According to other authors [37,49], some conduction electrons can be transferred directly to the Au NPs deposited on the surface of the semiconductor by ohmic interconnection or to carbon atoms on the graphene, and the electrons then react with the adsorbed $\mathrm{H}^{+}$ions to form $\mathrm{H}_{2}$. Thus, the synergetic effect between both co-catalysts, plasmonic Au nanoparticles and graphene, can effectively suppress photogenerated charge recombination, enlarge the active adsorption sites and reaction space, and consequently enhance the photocatalytic activity for $\mathrm{H}_{2}$ evolution [37,49]. In this regard, Wang et al. [49] reported that $\mathrm{Au} @ \mathrm{TiO}_{2}$-graphene composites had significantly increased the visible light absorption and enhanced the photocatalytic $\mathrm{H}_{2}$ production activity compared to the $\mathrm{Au} @ \mathrm{TiO}_{2}$. Luo et al. [37] found that by combining graphene and gold nanoparticles on $\mathrm{TiO}_{2}-\mathrm{P} 25$, the hydrogen production via water splitting increased nine times more than bare $\mathrm{TiO}_{2}-\mathrm{P} 25$.

In this research, the highest hydrogen production of the Au@commercial ZnO-graphene catalysts was $709 \mu \mathrm{mol} / \mathrm{hg}$ and was obtained by 10\%Au@ZnO commercial graphene under irradiation at $400 \mathrm{~nm}$. This enhancement represents a difference of $615 \mu \mathrm{mol} / \mathrm{hg}$ when compared to the highest amount obtained by the unmodified commercial $\mathrm{ZnO}$ catalyst ( $94 \mu \mathrm{mol} / \mathrm{hg}$ ), and the fact that the maximum production of the commercial catalyst was obtained at $400 \mathrm{~nm}$ (visible light) is an indication that the Au NPs are allowing the use of visible light [18,30,37]. On the other hand, appropriate visible light irradiation can induce the SPR effect on the gold nanoparticles and greatly enhance the electron capture capacity [37]. Both reasons affect the generation and separation of charges in photocatalysis, which results in the improvement of photocatalytic properties. The highest amount of hydrogen obtained with 1\%Au@commercial ZnO-graphene, 3\%Au@commercial ZnO-graphene, and 5\%Au@commercial ZnO-graphene catalysts was $405 \mu \mathrm{mol} / \mathrm{hg}, 529 \mu \mathrm{mol} / \mathrm{hg}$, and $589 \mu \mathrm{mol} / \mathrm{hg}$, respectively, under irradiation at $400 \mathrm{~nm}$.

In the case of Au@ZnO NPs-graphene catalysts, the highest hydrogen production measured was $759 \mu \mathrm{mol} / \mathrm{hg}$, representing a difference of $673 \mu \mathrm{mol} / \mathrm{hg}$ when compared to the maximum hydrogen production of the unmodified $\mathrm{ZnO} N$ s catalyst $(86 \mu \mathrm{mol} / \mathrm{hg})$, and was obtained with the $10 \% \mathrm{Au} @ \mathrm{ZnO}$ NPs-graphene catalyst at $400 \mathrm{~nm}$. The highest hydrogen production for 1\%Au@ZnO NPs-graphene, 3\%Au@ZnO NPs-graphene, and 5\%Au@ZnO NPs-graphene catalysts was $537 \mu \mathrm{mol} / \mathrm{hg}, 622 \mu \mathrm{mol} / \mathrm{hg}$, and $728 \mu \mathrm{mol} / \mathrm{hg}$, respectively. These results confirm once again that the presence of Au NPs allows the use of visible light to produce hydrogen.

Au@ZnO NWs-graphene catalysts showed the highest hydrogen production $(1127 \mu \mathrm{mol} / \mathrm{hg})$ with a gold loading of $10 \mathrm{wt} . \%$ at $400 \mathrm{~nm}$, representing a difference of $685 \mu \mathrm{mol} / \mathrm{hg}$ when compared to the unmodified ZnO NWs catalyst $(442 \mu \mathrm{mol} / \mathrm{hg})$. The highest amount of hydrogen produced at $400 \mathrm{~nm}$ with the 1\%Au@ZnO NWs-graphene,3\%Au@ZnO NWs-graphene, and 5\%Au@ZnO NWs-graphene catalysts was $701 \mu \mathrm{mol} / \mathrm{hg}, 828 \mu \mathrm{mol} / \mathrm{hg}$, and $944 \mu \mathrm{mol} / \mathrm{hg}$, respectively.

Under irradiation at $500 \mathrm{~nm}$ (Figure 6d), the maximum hydrogen production of the Au@commercial ZnO-graphene, Au@ZnO NPs-graphene, and Au@ZnO NWs-graphene catalysts was $628 \mu \mathrm{mol} / \mathrm{hg}$, $735 \mu \mathrm{mol} / \mathrm{hg}$, and $1079 \mu \mathrm{mol} / \mathrm{hg}$, respectively, with a gold loading of $10 \mathrm{wt} . \%$. These high hydrogen productions under low energy irradiation are an indication of the high photocatalytic activity of the composites, especially considering the high band-gap energy (3.37 eV) of ZnO. At wavelengths above 
$400 \mathrm{~nm}$, the water splitting depends mainly on the Au NPs, due to lack of energy to promote electrons from the valence band to the conduction band of $\mathrm{ZnO}$.
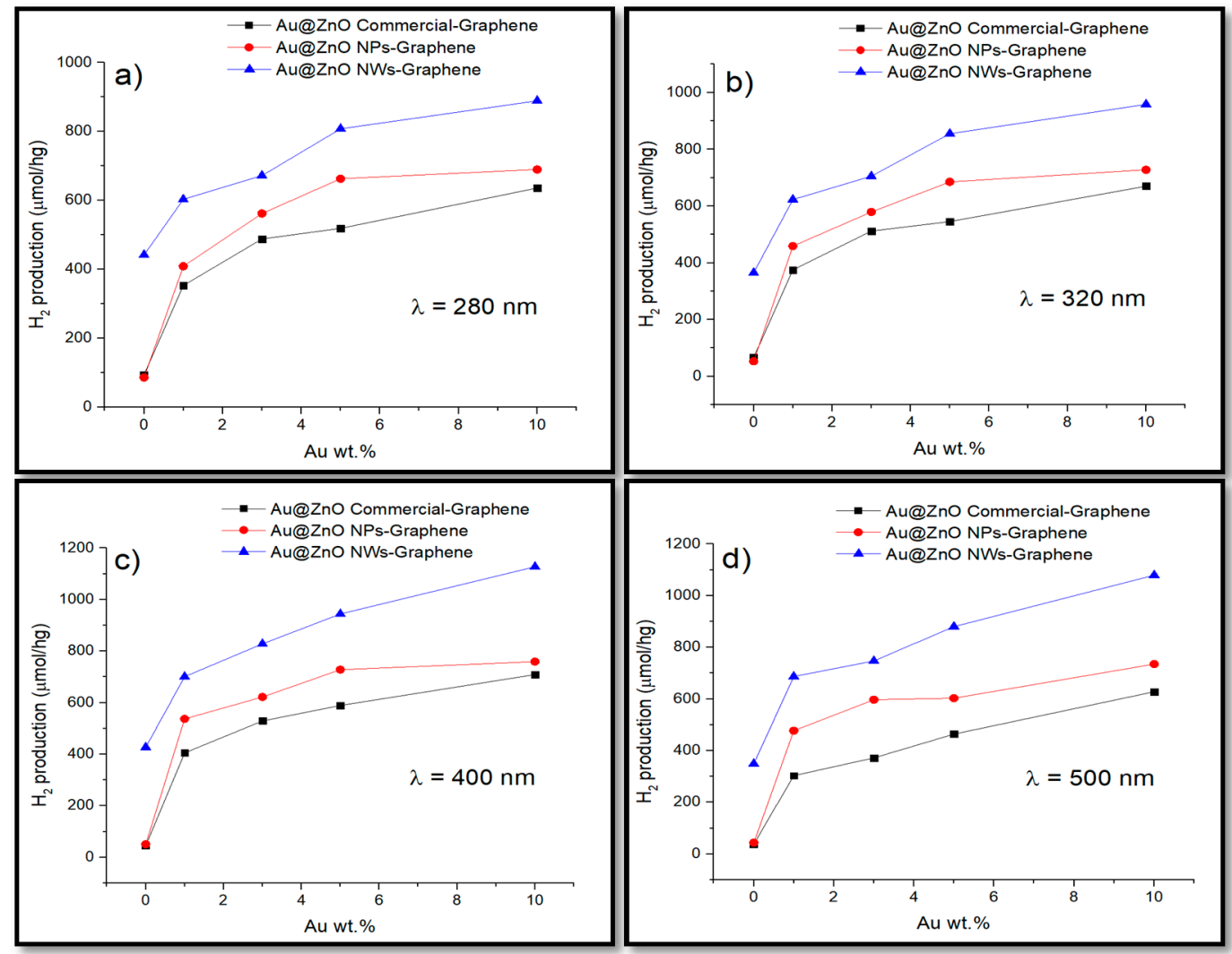

Figure 6. Photocatalytic hydrogen production of the different Au@ZnO-graphene catalysts under irradiation at $280 \mathrm{~nm}(\mathbf{a}), 320 \mathrm{~nm}(\mathbf{b}), 400 \mathrm{~nm}(\mathbf{c})$, and $500 \mathrm{~nm}(\mathbf{d})$.

In all cases, the highest amounts of hydrogen reported in this investigation were obtained with the catalysts with the highest surface area $\left(65 \mathrm{~m}^{2} \mathrm{~g}^{-1}\right.$ for 10\%Au@ commercial ZnO-graphene; $117 \mathrm{~m}^{2} \mathrm{~g}^{-1}$ for 10\%Au@ZnO NPs-graphene; $247 \mathrm{~m}^{2} \mathrm{~g}^{-1}$ for 10\%Au@ZnO NWs-graphene). Materials with high surface areas can be attained either by fabricating small particles or clusters where the surface-to-volume ratio of each particle is high, or by creating materials where the void surface area (pores) is high compared to the amount of bulk support material [50]. Multiple studies have demonstrated that the synthesis of high surface area catalysts lead to an increment in the hydrogen production due to the availability of more sites for the interaction of the water molecule with the catalyst $[49,50]$. In our research, this increase in surface area is primarily achieved by incorporating Au NPs and graphene on the surface of semiconductors.

In the case of $\mathrm{Au} / \mathrm{graphene}-\mathrm{TiO}_{2}$, over the years different possible mechanisms have been proposed for the production of hydrogen by water splitting (see Figure 7). One of the most widely accepted is that when compounds are irradiated with UV light (Figure 7A), a direct photoexcitation of $\mathrm{TiO}_{2}$ with photons with energy larger than the bandgap $(\lambda<380 \mathrm{~nm})$ leads to the generation of electrons in the conduction band, and electron holes in the valence band of the semiconductor [51]. The electron in the conduction band will move to the Au NPs, acting as electron buffers and catalytic sites for hydrogen generation [52]. When irradiated with visible light $(\lambda>500 \mathrm{~nm})$ photoexcitation of Au NPs occurs, and electrons from the Au NPs are injected into the $\mathrm{TiO}_{2}$ conduction band leading to the generation of holes in the $\mathrm{Au}$ NPs and electrons in the $\mathrm{TiO}_{2}$ conduction band [51,52]. Then, the water molecule gains the electrons in the conduction band and hydrogen is produced. Evidence of the proposed mechanism is the fact that the photocatalytic response for hydrogen generation is consistent with the absorption of the Au surface plasmon band. The incorporation of graphene creates a $\mathrm{p}-\mathrm{n}$ junction, which improves 
the separation of photogenerated charges, and the electrons are excited to the conduction band [26]. The electrons transferred from the conduction band of $\mathrm{TiO}_{2}$ are injected into the reduced graphene in a graphene/ $/ \mathrm{TiO}_{2}$ system because the graphene/graphene redox potential is slightly lower than the $\mathrm{CB}$ of $\mathrm{TiO}_{2}$ [26]. In addition, some conduction electrons of $\mathrm{TiO}_{2}$ likely transfer directly to the Au NPs deposited on the surface of the semiconductor by ohmic interconnection or to carbon atoms on the graphene sheets, and the electrons then react with the adsorbed $\mathrm{H}^{+}$ions to form $\mathrm{H}_{2}[25,26]$. This creates a synergistic effect between both co-catalysts, and they can effectively suppress photogenerated charge recombination, enlarge the active adsorption sites, and consequently enhance the photocatalytic activity $[16,25,26]$. When irradiated with visible light $(\lambda>500 \mathrm{~nm})$ (Figure $7 \mathrm{~B})$ photoexcitation of $\mathrm{Au}$ NPs occurs, and electrons from the Au are injected into the $\mathrm{ZnO}$ conduction band, leading to the generation of holes in the Au NPs and electrons in the $\mathrm{ZnO}$ conduction band [18]. The water molecule gains the electrons in the conduction band and hydrogen is produced. This proposed mechanism is an oversimplification since different studies [18-20] have determined that, due to the gold/semiconductor interfacial contact, the conduction band of the semiconductor undergoes shift toward more negative potentials [18]. Thus, the charge distribution between the Au NPs and the semiconductor causes a shift of the Fermi level toward more negative potentials [18,19].

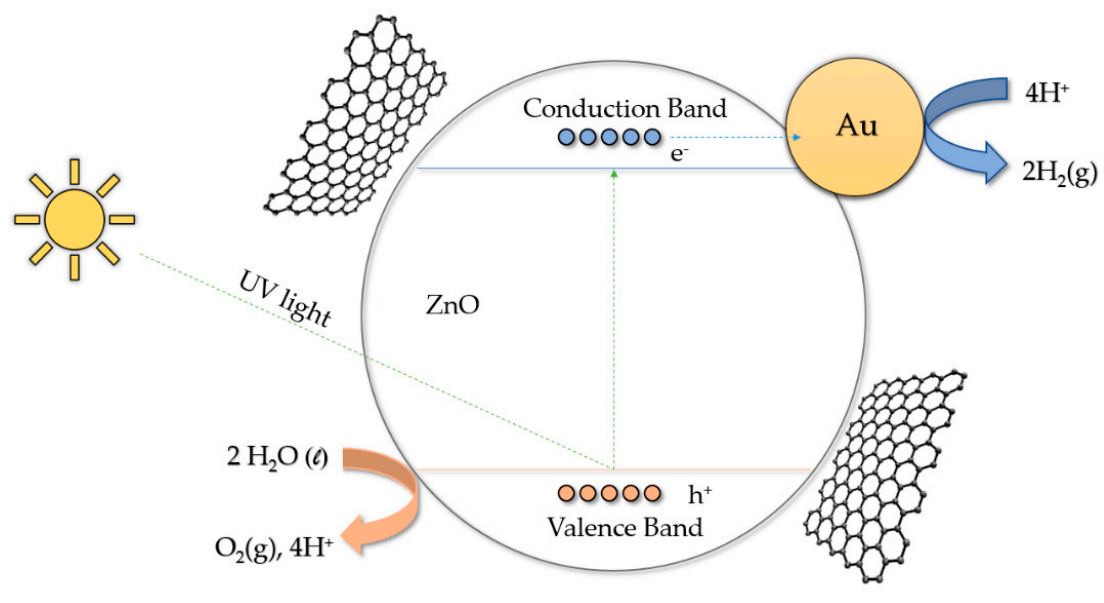

(A)

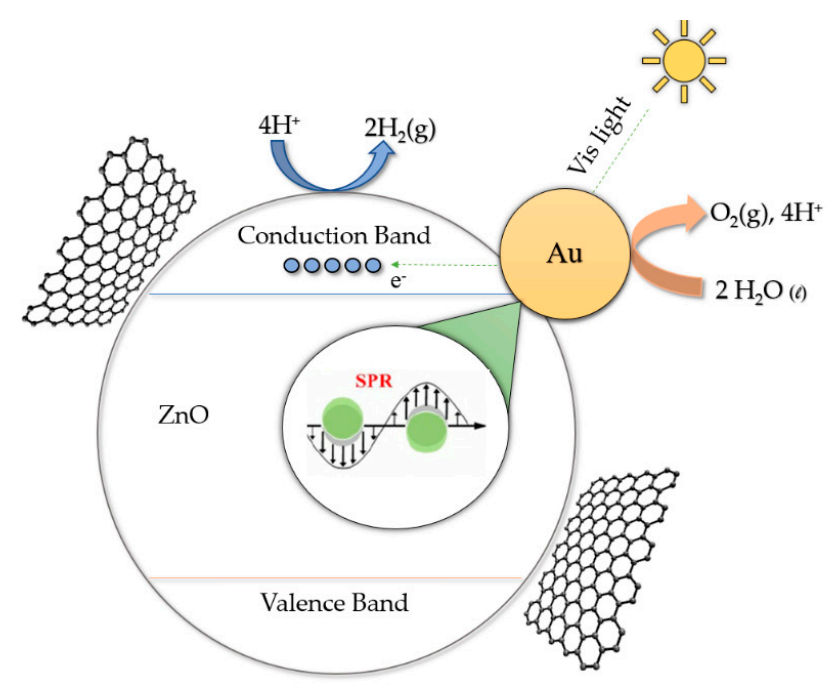

(B)

Figure 7. Possible mechanism of hydrogen production under ultraviolet (A) and visible (B) irradiation for the Au@ZnO-graphene systems. 
Table 2 shows the highest amounts of hydrogen obtained with Au@ZnO-graphene catalysts under the evaluated parameters. As already mentioned, and to the best of our knowledge, no results have been reported so far on hydrogen production by water splitting using Au@ZnO-graphene catalysts. Therefore, the results of this research are the first reported on the production of $\mathrm{H}_{2}$ using catalysts based on $\mathrm{ZnO}$ and graphene-gold. The materials studied in this research will have to be contrasted by other researchers to establish a much deeper knowledge that allows us to know the complex mechanism of hydrogen production with ternary compounds based on $\mathrm{ZnO}$.

Table 2. Highest amounts of hydrogen production via water splitting obtained with Au@ZnO-graphene catalysts under UV-vis light.

\begin{tabular}{|c|c|c|c|c|c|c|c|}
\hline Author & $\begin{array}{c}\mathrm{H}_{2} \\
\text { Production } \\
(\mu \mathrm{mol})\end{array}$ & $\begin{array}{l}\text { Source } \\
(\mathrm{nm})\end{array}$ & $\begin{array}{c}\text { Irradiation } \\
\text { Time (h) }\end{array}$ & $\begin{array}{l}\text { ZnO Crystal } \\
\text { Structure * }\end{array}$ & $\begin{array}{l}\text { Reaction } \\
\text { Mixture }\end{array}$ & $\underset{(w t . \%)}{\mathrm{Au}}$ & $\begin{array}{c}\text { Graphene } \\
\text { (wt.\%) }\end{array}$ \\
\hline $\begin{array}{l}\text { This work } \\
\text { ZnO } \\
\text { commercial }\end{array}$ & 709 & $\begin{array}{c}200>\lambda> \\
400\end{array}$ & 2 & W & $\begin{array}{c}\text { Water: } 0.5 \mathrm{M} \\
\mathrm{Na}_{2} \mathrm{~S}, 0.03 \mathrm{M} \\
\mathrm{Na}_{2} \mathrm{SO}_{3}\end{array}$ & 10 & 1 \\
\hline $\begin{array}{l}\text { This work } \\
\text { ZnO NPs }\end{array}$ & 759 & $\begin{array}{c}200>\lambda> \\
400\end{array}$ & 2 & W & $\begin{array}{c}\text { Water: } 0.5 \mathrm{M} \\
\mathrm{Na}_{2} \mathrm{~S}, 0.03 \mathrm{M} \\
\mathrm{Na}_{2} \mathrm{SO}_{3}\end{array}$ & 10 & 1 \\
\hline $\begin{array}{l}\text { This work } \\
\text { ZnO NWs }\end{array}$ & 1127 & $\begin{array}{c}200>\lambda> \\
700\end{array}$ & 2 & W & $\begin{array}{c}\text { Water: } 0.5 \mathrm{M} \\
\mathrm{Na}_{2} \mathrm{~S}, 0.03 \mathrm{M} \\
\mathrm{Na}_{2} \mathrm{SO}_{3}\end{array}$ & 10 & 1 \\
\hline
\end{tabular}

${ }^{*} \mathrm{~W}=$ Wurtzite.

\section{Conclusions}

Graphene and different amounts of gold nanoparticles were incorporated on the surface of synthesized $\mathrm{ZnO}$ supports ( $\mathrm{ZnO} \mathrm{NWs}, \mathrm{ZnO}$ NPs catalysts), and on the commercial form (commercial $\mathrm{ZnO}$ ). These catalysts were fully characterized by different techniques, and their photocatalytic activity was determined by measuring the hydrogen produced by water splitting under UV-vis irradiation.

The highest amount of the unmodified $\mathrm{ZnO}$ support was $442 \mu \mathrm{mol} / \mathrm{hg}$ and was obtained by the $\mathrm{ZnO}$ NWs catalyst under irradiation at $280 \mathrm{~nm}$. This unexpectedly high hydrogen production may be attributed to the morphology (nanowires) and possible defects in the crystalline structure. The maximum hydrogen production for the ZnO NPs and commercial ZnO catalysts was $94 \mu \mathrm{mol} / \mathrm{hg}$ and $86 \mu \mathrm{mol} / \mathrm{hg}$, respectively, at $280 \mathrm{~nm}$.

The maximum hydrogen production obtained with the commercial $\mathrm{ZnO}$ composites containing gold and graphene was $709 \mu \mathrm{mol} / \mathrm{hg}$ at $400 \mathrm{~nm}$ and was obtained with a gold loading of $10 \mathrm{wt} . \%$. The enhancement in the hydrogen production was 7.5 times higher than that reported by the commercial $\mathrm{ZnO}$.

The higher hydrogen production for the Au@ZnO NPs-graphene catalysts was $759 \mu \mathrm{mol} / \mathrm{hg}$ at $400 \mathrm{~nm}$ and was obtained with 10\%Au@ZnO NPs-graphene. The enhancement in the hydrogen production was 8.8 times higher than that reported by the ZnO NPs catalyst.

In the case of the Au@ZnO NWs-graphene composites, the higher hydrogen production (1127 $\mu \mathrm{mol} / \mathrm{hg})$ was obtained with the 10\%Au@ZnO NWs-graphene under irradiation at $400 \mathrm{~nm}$.

The catalysts did not show a reduction in the surface area nor in the hydrogen production with the increment in gold loadings and incorporation of graphene. These results suggest that the best graphene and gold loading for the Au@ZnO-graphene catalysts could be higher than 1 and 10 wt.\%, respectively.

Author Contributions: Conceptualization, A.M., F.M.; methodology, A.M., F.M.; formal analysis, A.M., F.M.; investigation, A.M., J.C.A., K.F., L.S.-V., E.R., C.M.; resources, F.M., C.M., F.I.T.P., M.C., J.D.; writing-original draft preparation, A.M.; writing-review and editing, A.M., F.M.; supervision, A.M., F.M.; project administration, F.M.; funding acquisition, F.M., C.M., M.C., J.D., F.I.T.P. All authors have read and agreed to the published version of the manuscript. 
Funding: Financial support provided by the US DoE, through the Massie Chair project at University of Turabo, US Department of Defense, under contract W911NF-14-1-0046, and from the Ministerio de Economía y Competitividad (MINECO) of Spain, through the grant ENE2014-57977-C2-1-R, are gratefully acknowledged.

Acknowledgments: Technical assistance of I. Poveda from "Servicio Interdepartamental de Investigacion, SIdI" at UAM, is gratefully acknowledged. The facilities provided by the National Center for Electron Microscopy at Complutense University of Madrid (Spain) and the Materials Characterization Center at University of Puerto Rico are gratefully acknowledged.

Conflicts of Interest: The authors declare no conflict of interest.

\section{References}

1. Nicoletti, G.; Arcuri, N.; Nicoletti, G.; Bruno, R. A technical and environmental comparison between hydrogen and some fossil fuels. Energy Convers. Manag. 2015, 89, 205-213. [CrossRef]

2. Staffell, I.; Scamman, D.; Abad, A.V.; Balcombe, P.; Dodds, P.E.; Ekins, P.; Shah, N.; Ward, K.R. The role of hydrogen and fuel cells in the global energy system. Energy Environ. Sci. 2019, 12, 463-491. [CrossRef]

3. Wismann, S.T.; Engbæk, J.S.; Vendelbo, S.B.; Bendixen, F.B.; Eriksen, W.L.; Aasberg-Petersen, K.; Frandsen, C.; Chorkendorff, I.; Mortensen, P.M. Electrified methane reforming: A compact approach to greener industrial hydrogen production. Science 2019, 364, 756-759. [CrossRef]

4. Bae, S.; Jang, J.-E.; Lee, H.-W.; Ryu, J. Tailored Assembly of Molecular Water Oxidation Catalysts on Photoelectrodes for Artificial Photosynthesis. Eur. J. Inorg. Chem. 2019, 2019, 2040-2057. [CrossRef]

5. Wang, D.; Farnum, B.H.; Dares, C.J.; Meyer, T.J. Chemical approaches to artificial photosynthesis: A molecular, dye-sensitized photoanode for $\mathrm{O} 2$ production prepared by layer-by-layer self-assembly. J. Chem. Phys. 2020, 152, 244706. [CrossRef]

6. Etacheri, V.; Di Valentin, C.; Schneider, J.; Bahnemann, D.W.; Pillai, S.C. Visible-light activation of TiO2 photocatalysts: Advances in theory and experiments. J. Photochem. Photobiol. C Photochem. Rev. 2015, 25, 1-29. [CrossRef]

7. Liao, Y.T.; Van Chi, N.; Ishiguro, N.; Young, A.P.; Tsung, C.K.; Wu, K.C.W. Engineering a homogeneous alloy-oxide interface derived from metal-organic frameworks for selective oxidation of 5-hydroxymethylfurfural to 2,5-furandicarboxylic acid. Appl. Catal. B Environ. 2020, 270, 118805. [CrossRef]

8. Konnerth, H.; Matsagar, B.M.; Chen, S.S.; Prechtl, M.H.; Shieh, F.-K.; Wu, K.C.-W. Metal-organic framework (MOF)-derived catalysts for fine chemical production. Coord. Chem. Rev. 2020, 416, 213319. [CrossRef]

9. Doustkhah, E.; Lin, J.; Rostamniaa, S.; Len, C.; Luque, R.; Luo, X.; Bando, Y.; Wu, K.C.-W.; Kim, J.; Yamauchi, Y.; et al. Development of Sulfonic-Acid-Functionalized Mesoporous Materials: Synthesis and Catalytic Applications. Chem. A Eur. J. 2018, 25, 1614-1635. [CrossRef]

10. Chueh, C.-C.; Chen, C.-I.; Su, Y.-A.; Konnerth, H.; Gu, Y.-J.; Kung, C.-W.; Wu, K.C.-W. Harnessing MOF materials in photovoltaic devices: Recent advances, challenges, and perspectives. J. Mater. Chem. A 2019, 7, 17079-17095. [CrossRef]

11. Lee, C.-C.; Chen, C.-I.; Liao, Y.-T.; Wu, K.C.-W.; Chueh, C.-C. Enhancing Efficiency and Stability of Photovoltaic Cells by Using Perovskite/Zr-MOF Heterojunction Including Bilayer and Hybrid Structures. Adv. Sci. 2019, 6, 1801715. [CrossRef] [PubMed]

12. Zhou, T.; Wang, J.; Chen, S.; Bai, J.; Li, J.; Zhang, Y.; Li, L.; Xia, L.; Rahim, M.; Xu, Q.; et al. Bird-nest structured $\mathrm{ZnO} / \mathrm{TiO} 2$ as a direct $\mathrm{Z}$-scheme photoanode with enhanced light harvesting and carriers kinetics for highly efficient and stable photoelectrochemical water splitting. Appl. Catal. B Environ. 2020, 267, 118599. [CrossRef]

13. Li, Y.; Liu, Z.; Zhang, J.; Guo, Z.; Xin, Y.; Zhao, L. 1D/0D WO3/CdS heterojunction photoanodes modified with dual co-catalysts for efficient photoelectrochemical water splitting. J. Alloys Compd. 2019, 790, 493-501. [CrossRef]

14. Saleh, S.M. ZnO nanospheres based simple hydrothermal route for photocatalytic degradation of azo dye. Spectrochim. Acta Part A Mol. Biomol. Spectrosc. 2019, 211, 141-147. [CrossRef]

15. Fahimi, Z.; Moradlou, O. Fabrication of ZnO@C foam: A flexible free-standing electrode for energy storage devices. Mater. Des. 2020, 189, 108525. [CrossRef]

16. Ali, A.; Ammar, M.; Ali, M.; Yahya, Z.; Javaid, M.Y.; Hassan, S.U.; Ahmed, T. Mo-doped ZnO nanoflakes on Ni-foam for asymmetric supercapacitor applications. RSC Adv. 2019, 9, 27432-27438. [CrossRef] 
17. Nguyen, C.H.; Tran, M.L.; Van Tran, T.T.; Juang, R.-S. Enhanced removal of various dyes from aqueous solutions by UV and simulated solar photocatalysis over $\mathrm{TiO}_{2} / \mathrm{ZnO} / \mathrm{rGO}$ composites. Sep. Purif. Technol. 2020, 232, 115962. [CrossRef]

18. Machín, A.; Cotto, M.; Duconge, J.; Arango, J.C.; Morant, C.; Pinilla, S.; Soto-Vázquez, L.; Resto, E.; Márquez, F.M. Hydrogen production via water splitting using different Au@ZnO catalysts under UV_Vis irradiation. J. Photochem. Photobiol. A Chem. 2018, 353, 385-394. [CrossRef]

19. Han, C.; Qi, M.-Y.; Tang, Z.-R.; Gong, J.; Xu, Y.-J. Gold nanorods-based hybrids with tailored structures for photoredox catalysis: Fundamental science, materials design and applications. Nano Today 2019, 27, 48-72. [CrossRef]

20. Elahi, N.; Kamali, M.; Baghersad, M.H. Recent biomedical applications of gold nanoparticles: A review. Talanta 2018, 184, 537-556. [CrossRef]

21. Nakamura, M.; Oyane, A.; Kuroiwa, K.; Kosuge, H. Fabrication of gold-calcium phosphate composite nanoparticles through coprecipitation mediated by amino-terminated polyethylene glycol. Colloids Surf. B Biointerfaces 2020, 194, 111169. [CrossRef] [PubMed]

22. Yanguas, S.P.; Machín, A.; Park, S.-H.; Arango, J.C.; Nicolosi, V.; Linares, F.M.; Morant, C. TiO $\mathrm{T}_{2}-\mathrm{Based}$ Nanomaterials for the Production of Hydrogen and the Development of Lithium-Ion Batteries. J. Phys. Chem. B 2017, 122, 972-983. [CrossRef]

23. Choudhary, M.K.; Kataria, J.; Sharma, S. Novel Green Biomimetic Approach for Preparation of Highly Stable Au-ZnO Heterojunctions with Enhanced Photocatalytic Activity. ACS Appl. Nano Mater. 2018, 1, 1870-1878. [CrossRef]

24. Luo, L.-M.; Zhang, R.-H.; Chen, D.; Hu, Q.-Y.; Zhang, X.; Yang, C.; Zhou, X.-W. Hydrothermal synthesis of $\mathrm{PdAu}$ nanocatalysts with variable atom ratio for methanol oxidation. Electrochim. Acta 2018, 259, $284-292$. [CrossRef]

25. Devrim, Y.; Arıca, E.D.; Albostan, A. Graphene based catalyst supports for high temperature PEM fuel cell application. Int. J. Hydrog. Energy 2018, 43, 11820-11829. [CrossRef]

26. Nguyen, N.-T.; Zheng, D.-D.; Chen, S.-S.; Chang, C.-T. Preparation and Photocatalytic Hydrogen Production of Pt-Graphene/TiO2 Composites from Water Splitting. J. Nanosci. Nanotechnol. 2018, 18, 48-55. [CrossRef]

27. Tien, H.N.; Luan, V.H.; Hoa, L.T.; Khoa, N.T.; Hahn, S.H.; Chung, J.S.; Shin, E.W.; Hur, S.H. One-pot synthesis of a reduced graphene oxide-zinc oxide sphere composite and its use as a visible light photocatalyst. Chem. Eng. J. 2013, 229, 126-133. [CrossRef]

28. Ong, W.-J.; Voon, S.-Y.; Tan, L.-L.; Goh, B.T.; Yong, S.-T.; Chai, S.-P. Enhanced Daylight-Induced Photocatalytic Activity of Solvent Exfoliated Graphene (SEG)/ZnO Hybrid Nanocomposites toward Degradation of Reactive Black 5. Ind. Eng. Chem. Res. 2014, 53, 17333-17344. [CrossRef]

29. Haldorai, Y.; Shim, J.-J. Supercritical fluid mediated synthesis of highly exfoliated graphene/ZnO composite for photocatalytic hydrogen production. Mater. Lett. 2014, 133, 24-27. [CrossRef]

30. Zeng, D.; Gong, P.; Chen, Y.; Wang, C.; Peng, D.-L. Preparation of multi-branched Au-ZnO hybrid nanocrystals on graphene for enhanced photocatalytic performance. Mater. Lett. 2015, 161, 379-383. [CrossRef]

31. Wang, P.; Wu, D.; Ao, Y.; Wang, C.; Hou, J. ZnO nanorod arrays co-loaded with Au nanoparticles and reduced graphene oxide: Synthesis, characterization and photocatalytic application. Colloids Surf. A Physicochem. Eng. Asp. 2016, 492, 71-78. [CrossRef]

32. Roy, P.; Periasamy, A.P.; Liang, C.-T.; Chang, H.-T. Synthesis of Graphene-ZnO-Au Nanocomposites for Efficient Photocatalytic Reduction of Nitrobenzene. Environ. Sci. Technol. 2013, 47, 6688-6695. [CrossRef] [PubMed]

33. Lin, C.-C.; Li, Y.-Y. Synthesis of ZnO nanowires by thermal decomposition of zinc acetate dihydrate. Mater. Chem. Phys. 2009, 113, 334-337. [CrossRef]

34. Nejati, K.; Rezvani, Z.; Pakizevan, R. Synthesis of ZnO Nanoparticles and Investigation of the Ionic Template Effect on Their Size and Shape. Int. Nano Lett. 2011, 1, 75-81. [CrossRef]

35. Naldoni, A.; D’Arienzo, M.; Altomare, M.; Marelli, M.; RScotti Morazzoni, F.; Selli, E.; Del Santo, V. Pt and $\mathrm{Au} / \mathrm{TiO} 2$ photocatalysts for methanol reforming: Role of metal nanoparticles in tuning charge trapping properties and photoefficiency. Appl. Catal. B Environ. 2013, 130, 239-248. [CrossRef]

36. Suryanarayana, C.; Norton, M.G. X-ray Diffraction; Plenum Press: New York, NY, USA, 1998. 
37. Luo, J.; Li, D.; Yang, Y.; Liu, H.; Chen, J.; Wang, H. Preparation of Au/reduced graphene oxide/hydrogenated $\mathrm{TiO} 2$ nanotube arrays ternary composites for visible-light-driven photoelectrochemical water splitting. J. Alloys Compd. 2016, 661, 380-388. [CrossRef]

38. Wen, Y.; Ding, H.; Shan, Y. Preparation and visible light photocatalytic activity of $\mathrm{Ag} / \mathrm{TiO}_{2} / \mathrm{graphene}$ nanocomposite. Nanoscale 2011, 3, 4411. [CrossRef]

39. Dang, H.; Dong, X.; Dong, Y.; Huang, J. Facile and green synthesis of titanate nanotube/graphene nanocomposites for photocatalytic H2 generation from water. Int. J. Hydrog. Energy 2013, 38, 9178-9185. [CrossRef]

40. Briggs, D.; Seah, M. Practical Surface Analysis; Wiley: New York, NY, USA, 1994.

41. Liu, H.; Xu, Q.; Yan, C.; Qiao, Y. Corrosion behavior of a positive graphite electrode in vanadium redox flow battery. Electrochim. Acta 2011, 56, 8783-8790. [CrossRef]

42. Desimoni, E.; Casella, I.G.; Morone, A.; Salvi, A.M. XPS determination of oxygen-containing functional groups on carbon-fibre surfaces and the cleaning of these surfaces. Surf. Interface Anal. 1990, 15, 627-634. [CrossRef]

43. Baruah, S.; Dutta, J. Effect of seeded substrates on hydrothermally grown ZnO nanorods. J. Sol-Gel Sci. Technol. 2009, 50, 456-464. [CrossRef]

44. Baruah, S.; Mahmood, M.A.; Myint, M.T.Z.; Bora, T.; Dutta, J. Enhanced visible light photocatalysis through fast crystallization of zinc oxide nanorods. Beilstein J. Nanotechnol. 2010, 1, 14-20. [CrossRef] [PubMed]

45. Choi, W.; Termin, A.; Hoffmann, M.R. The Role of Metal Ion Dopants in Quantum-Sized $\mathrm{TiO}_{2}$ : Correlation between Photoreactivity and Charge Carrier Recombination Dynamics. J. Phys. Chem. 1994, 98, 13669-13679. [CrossRef]

46. Slamet, S.; Kusrini, E.; Afrozi, A.S.; Ibadurrohman, M. Photocatalytic Hydrogen Production from Glycerol-water over Metal Loaded and Non-metal Doped Titanium Oxide. Int. J. Technol. 2015, 6, 520. [CrossRef]

47. Bora, T.; Zoepfl, D.; Dutta, J. Importance of Plasmonic Heating on Visible Light Driven Photocatalysis of Gold Nanoparticle Decorated Zinc Oxide Nanorods. Sci. Rep. 2016, 6, 26913. [CrossRef]

48. Li, L.; Yu, L.; Lin, Z.; Yang, G.W. Reduced $\mathrm{TiO}_{2}$-Graphene Oxide Heterostructure as Broad Spectrum-Driven Efficient Water-Splitting Photocatalysts. ACS Appl. Mater. Interfaces 2016, 8, 8536-8545. [CrossRef]

49. Wang, Y.; Yu, J.; Xiao, W.; Li, Q. Microwave-assisted hydrothermal synthesis of graphene based Au-TiO2 photocatalysts for efficient visible-light hydrogen production. J. Mater. Chem. A 2014, 2,3847-3855. [CrossRef]

50. Kołodziejczak-Radzimska, A.; Jesionowski, T. Zinc Oxide-From Synthesis to Application: A Review. Materials 2014, 7, 2833-2881. [CrossRef]

51. Dosado, A.G.; Chen, W.-T.; Chan, A.; Sun-Waterhouse, D.; Waterhouse, G.I. Novel Au/TiO2 photocatalysts for hydrogen production in alcohol-water mixtures based on hydrogen titanate nanotube precursors. J. Catal. 2015, 330, 238-254. [CrossRef]

52. Silva, C.G.; Juárez, R.; Marino, T.; Molinari, R.; García, H.; García, H. Influence of Excitation Wavelength (UV or Visible Light) on the Photocatalytic Activity of Titania Containing Gold Nanoparticles for the Generation of Hydrogen or Oxygen from Water. J. Am. Chem. Soc. 2011, 133, 595-602. [CrossRef]

(C) 2020 by the authors. Licensee MDPI, Basel, Switzerland. This article is an open access article distributed under the terms and conditions of the Creative Commons Attribution (CC BY) license (http://creativecommons.org/licenses/by/4.0/). 